\title{
THE NEW PRESIDENT OF THE ROYAL COLLEGE OF SURGEONS.
}

The name of Henry Trentham Butlin is so familiar to laryngologists in connection with the work that he has done in regard to the pathology and the surgery of the larynx, that they will feel an especial pride in his election to the presidential chair by the Council of the Royal College of Surgeons. Mr. Butlin has receired numerous academical honours, which he has honestly earned by devoted and laborious work in the interests of such institutions as the British Medical Association and the University of London. For many years he had the charge of the Throat Department at St. Bartholomew's Hospital, and numbers of his pupils can still bear witness as to the energy and enthusiasm which he displayed in the instruction he afforded them. To him more than to anyone else is due the evolution and perfection of the operation of thyrotomy, especially in connection with early intra-laryngeal epithelioma, the valuable effects of which have been well exemplified in the results obtained by him and by Sir Felix Semon. Among Mr. Butlin's earlier works was one on carcinoma and sarcoma of the larynx, which was a sequel to his Jacksonian prize essay on carcinoma and sarcoma in general. He was one of the earliest presidents of the Laryngological Society of London, and he has been from time to time an active participator in its clinical discussions. The members of the Society were always impressed by the well-weighed utterances of his own views and by the dignified and courteous consideration which he was ever ready to give to the views expressed by even the least experienced speakers. 'Those' who know him best will realise best how well he is calculatel to exercise a healthy influence in the presidential chair to which, we hear without surprise, his election was unanimous.

\section{A MEMORIAL TABLET ON THE BIRTH-PLACE OF THE LATE SIR MORELL MACKENZIE.}

Any tribute to the memory of this illustrious pioneer in laryngology will be a source of gratification to laryngologists all over the world. On Monday, July 19, a tablet was placed on the house in Leytonstone where Sir Morell Mackenzie was born. The movement was initiated by the Leyton Urban Ratepayers' Association, and the unveiling of the tablet was performed, with appropriate remarks. by Mr. Morgan, formerly Member of Parliament for the Romford 